\title{
Secciones y disecciones epistemológicas del discurso jurídico: un estudio desde la iusfilosofía crítica
}

\author{
Epistemological Sections and Dissections of Legal \\ Discourse. A Study from the Critical Legal Studies \\ Secções e dissecções epistemológicas do discurso \\ jurídico. Estudo desde a iusfilosofia crítica
}

Héctor Gonzalo Ana Dobratinich*

Fecha de recepción: 9 de febrero de 2019

Fecha de aprobación: 19 de marzo de 2019

Doi: http://dx.doi.org/10.12804/revistas.urosario.edu.co/anidip/a.8496

Para citar: Ana Dobratinich, H. G. (2019). Secciones y disecciones
epistemológicas del discurso jurídico: un estudio desde la iusfilosofía
crítica. ANIDIP (7), 91-115. Doi: http://dx.doi.org//10.12804/revistas.
urosario.edu.co/anidip/a.8496

\section{Resumen}

Entender el derecho como una práctica social específica de carácter discursivo nos permite analizarlo desde una óptica diferente, desde la cual pueden observarse las sutiles e intencionadas estructuras de su formación. Los tonos circunstanciales, las frases de poca importancia, las metáforas que embellecen, en definitiva, todos esos recursos que cualquier lector pasaría por alto en su ansiosa búsqueda por entender la finalidad del texto. El discurso jurídico está contaminado de todas estas indeterminaciones que pululan por sus enunciados, frases emotivas, conceptos vagos y el uso de figuras lingüísticas extraordinarias; de este modo, el derecho expresa y se resignifica mucho más allá de lo que puede leerse superficialmente en sus enunciados.

Intertextualidad e interpretación serán dos aspectos importantes para poder analizar la conformación del fenómeno jurídico, así como también un tercer elemento, el ficcional, en donde el derecho se eclipsa bajo formas diferentes de las que su discurso 
parece hacer alusión. Esta dualidad contradictoria, lejos de ser considerada una falla que atenta contra su existencia, será un elemento fundamental para su constante estructuración, funcionamiento y reproducción.

Palabras clave: discurso, iusfilosofía crítica, intertextualidad, interpretación, ficción

\section{Abstract}

Understanding the law as a specific social practice of discursive nature allows analyzing it from a different perspective: the observation of its formation structures. The circumstantial tones, the phrases of little importance, the metaphors that embellish, in short, all the resources that any reader would ignore. The legal discourse is contaminated by all these indeterminacies that swarm by their statements, emotional phrases, vague concepts, and the use of extraordinary linguistic figures. The law expresses and resignifies far beyond what can be read superficially in its statements. Intertextuality and interpretation are two essential aspects to analyze the configuration of the legal phenomenon, as well as a third element, the fictional one, where the law eclipses in different ways from which its discourse seems to refer. This contradictory duality, far from being considered a fault that threatens its existence, will be a fundamental element for its constant structuring, functioning, and reproduction.

Keywords: Discourse, critical legal studies, intertextuality, interpretation, fiction.

\section{Resumo}

Entender o direito como uma prática social específica de carácter discursivo permite-nos analisa-lo desde uma ótica diferente, desde a qual podem se observar as sutis e intencionadas estruturas de sua formação. Os tons circunstanciais, as frases de pouca importância, as metáforas que embelecem, em definitiva todos esses recursos que qualquer leitor desatenderia em sua ansiosa busca por entender a finalidade do texto. O discurso jurídico está contaminado de todas estas indeterminações que pululam por seus enunciados, frases emotivas, conceitos vagos e uso de figuras linguísticas extraordinárias. O direito expressa e se re-significa muito para além do que pode ler-se superficialmente em seus enunciados.

Intertextualidade e interpretação serão dois aspectos importantes para poder analisar a conformação do fenômeno jurídico, assim como também um terceiro elemento, o ficcional, onde o direito se eclipsa sob formas diferentes das que seu discurso parece fazer alusão. Esta dualidade contraditória, longe de ser considerada uma falha que atenta contra sua existência, será um elemento fundamental para sua constante estruturação, funcionamento e reprodução.

Palavras-chave: discurso, iusfilosofia crítica, intertextualidade, interpretação, ficção 


\section{Intertextualidad e interpretación}

La literatura no es agotable, por la suficiente y simple razón de que un solo libro no lo es. El libro no es un ente incomunicado: es una relación, es un eje de innumerables relaciones.

Nota sobre (hacia) Bernard Shaw.- Jorge Luis Borges

\section{Murmullos epistemológicos}

La palabra no puede abarcar la complejidad desde los límites de sus categorías analíticas, pues el sentido cambia en un constante devenir (Nietzsche, 1990, p. 25). $\mathrm{Si}$ bien es absurdo negar la figura del autor porque hay obra, sí podremos invisibilizarlo a los fines de otorgar preponderancia al discurso (Borges, 1974, p. 641); por tanto, el salto del autor es inmediato porque su constitución está en su producción. No hay voces de autoridad, sino escritos en circulación (Borges, 1974, p. 698).

La lectura vehiculiza la forma en que luego se constituirá la obra; por ello se destaca y resalta el rol que cumple el lector; un lector contextualizado y creado en cada una de sus lecturas.

Los significados en constante movimiento, las capas textuales sobre las cuales se superponen y conviven los saberes, el recorrido caótico, arbitrario e incierto en que se vinculan las obras y, en definitiva, la múltiple y necesaria intertextualidad determinan esta articulación explícita o implícita de varios textos entre sí, que será un rasgo distinto en el entramado que permite la estructuración y funcionamiento de los saberes. Los códigos que se van intercalando en los textos darán la impronta dialógica que habita en cada uno de ellos; en este orden de ideas, la polifonía es intervenida tanto a nivel intersticial de la obra (espacios, tiempo, personajes) como en su externalidad (autor, género). La confusión de voces permitirá esa comunicación desde una horizontalidad que rompe con toda una perspectiva heredada de asepsia metodológica y linealidad temporal, capaz de organizar la forma en que comprendemos la cultura.

El proceso remite a un laberinto de lecturas que complejizan el acceso a la punta del hilo, su "ఏ̊ $\rho \chi \eta ́$ " literaria. Las intermediaciones textuales se atomizan en ramificaciones de sentido muy sutiles. La dificultad por poder establecer el punto inicial encuentra su fundamentación en las superpuestas capas intertextuales que van sedimentándose y formando un producto cuyos puntos de inicio y fin son difíciles de establecer.

Poder remover las superposiciones textuales no solo nos explica cómo se ha formado el discurso, sino también nos permite entender el modo en que conocemos y 
nos vinculamos con nuestro entorno, es decir, la funcionalidad. Por tanto, el discurso debe ser fragmentado a nivel metalingüístico, teniendo en cuenta que su conceptualización es de por sí necesaria para diseccionar la forma en que se organiza y conocer sus propósitos e intereses.

Estas dos instancias nos introducen en los estudios y perspectivas analíticas de Michael Foucault y Paul Ricoeur, partiendo de perspectivas diferentes más no excluyentes entre sí. El abordaje foucaultiano irá dirigido a las condiciones de formación del discurso, en tanto que Paul Ricœur pondrá el foco en las subjetividades intervinientes e intervenidas en el discurso.

\section{Lo discursivo desde una perspectiva foucaultiana}

En su texto El orden del discurso, Foucault propone que el análisis del espacio discursivo debe realizarse en primer lugar desde un "conjunto crítico", capaz de mostrar cómo se han formado las necesidades, prohibiciones, limitaciones, coacciones y desplazamientos trastocados en el discurso. En segundo lugar, se exige un "conjunto genealógico" que intente establecer cómo se ha formado el discurso y cuáles fueron los medios de dicho desarrollo.

El trinomio saber-poder-discurso será una constante desde la cual el autor francés estructurará gran parte de su pensamiento. El orden en que se encadenan los enunciados no será un mero acto de organización lingüística y estructuras sintácticas sostenidas por toda una perspectiva estructuralista, sino hechos estratégicos que guardan estrecha vinculación con los intereses de los sujetos participantes: "El discurso no es simplemente aquello que traduce las luchas o los sistemas de dominación, sino aquello por lo que, y por medio de lo cual se lucha, aquel poder del que quiere uno adueñarse" (Foucault, 1996, p. 15).

La producción discursiva es controlada y disgregada a través de minuciosos procedimientos que velan por su contingencia e historicidad, a los fines de darle una cobertura de aparente objetividad. En este sentido es que las estrategias pedagógicas permiten el ingreso de los individuos a todos los discursos, lo cual es una forma política de mantener o trastocar los discursos mediados por el saber y el poder (Foucault, 1996, pp. 45-46).

Foucault entiende que el conjunto de enunciados constituyentes de un discurso responden a un mismo sistema de formación, que no solo expone los significados del discurso sino que también exige silencios, vacíos, límites, recortes y exclusiones. Para el autor, los discursos no se desarrollan como actos individuales o sistemas cerrados, sino que "los discursos religiosos, judiciales, terapéuticos, y en cierta parte también los políticos, no son disociables de esa puesta en escena de un ritual que 
determina para los sujetos que hablan tanto las propiedades singulares como los papeles convencionales" (Foucault, 1996, p. 41).

El análisis foucaultiano pone sobre relieve la intertextualidad que opera en la formación de los discursos, en donde los significados y enunciados son mediados por las instancias de poder que visibilizan e invisibilizan sus funciones: "Todos ellos, y dentro de su heterogeneidad, no forman ni una obra ni un texto, sino una singular querella, un enfrentamiento, una relación de poder, una batalla de discursos y a través de los discursos" (Foucault, 2006, p. 18).

Estos entramados epistemológicos, propuestos por el autor francés, pueden ser trasladables al derecho, el cual se nos presenta narrativamente. ${ }^{1}$ Acontece como un terreno discursivo pasible de ser indagado desde el análisis lingüístico. En torno a ello, Marí (1980) expone:

La realidad es más compleja que las diversas formas que la teoría jurídica -especializada o no- o cualquier otro de los dispositivos que se involucran el término lato "derecho" (se trate del corpus normativo o de la maquinaria judicial) dicen poner en juego para describirla, sistematizarla, acuñarla o aplicarla (p. 56).

Es así, que en estas instancias de análisis epistemológicos y casi de manera indirecta y desintencionada, nos vemos conducidos a reformular y deconstruir la manera en que conceptualizamos al derecho.

\section{Entramados discursivos del derecho}

Bajo esta nueva perspectiva, el derecho se nos presenta y desenvuelve como una práctica social específica de índole discursiva (Cárcova, 2012), en donde su formación está intervenida por un complejo entramado de discursos. Los términos que participan en dichos enunciados están en constante movimiento semántico, listos para ser constituidos y reformulados por la participación de otros saberes. Por ello consideramos que el universo jurídico debe ser analizado desde la totalidad social que lo contiene y forma, a través de una perspectiva multidisciplinaria, caracterizada por la superposición e interferencia de los diferentes tipos de discursos en donde se despliega.

El modo en que categorizamos y planteamos la realidad moldeará nuestro pensamiento e implicará una determinada forma de actuar en sociedad. Toda intención analítica intenta la supresión de la arbitrariedad y contingencia del lenguaje, mediante "caprichosas" categorías; por su parte, las conceptualizaciones amplían la

Véase Yo, Pierre Rivière, habiendo deģollado a mi madre, a mi hermana y a mi hermano (Foucault, 2016). 
participación de los fenómenos, pero al mismo tiempo excluyen otros casi de manera simultánea, en cuanto damos cuenta de la arbitrariedad opacada en categorías pretendidamente universales, puras y transparentes, visibilizamos una sofisticada forma de la ficción.

Este posicionamiento intenta atomizar una disciplina como la jurídica, difícilmente matizable, dado su sistema de autolegitimación integrado por diferentes niveles (Entelman, 1982). Dentro de esta posición que comprende al derecho como un fenómeno signado por la intertextualidad, se pretende desmembrar las dimensiones discursivas participantes y exteriorizar el modo en que se construyen; ya no se pondrá el foco únicamente en la estructura de las disciplinas, sino también en la función que éstas cumplen. Es en esta funcionalidad y en las vinculaciones que se pueden establecer entre ellas es donde se puede articular y dar cuentas de los diferentes discursos que participan en la construcción del saber jurídico.

Desde un punto de vista tanto teórico como pragmático, debe pensarse el ámbito del derecho desde una visión integradora, capaz de dar cuenta de todos los insumos que intervienen en su formación. Adentrarse en su estudio puede implicar una tarea nada sencilla. El lenguaje específico, los usos concretos, los modismos característicos y las diferentes categorías emergentes distan de ser un espacio fácilmente asequible, no solo a quienes participan activamente en el ejercicio del derecho en sus múltiples formas, sino también para aquellos que nunca han tenido un acercamiento directo con estos espacios.

Pensar en el derecho como una totalidad lleva consigo conocer las áreas que lo conforman como tal y lo constituyen como un conjunto sistemático; además, requiere necesariamente partir de bases epistemológicas y metodológicas capaces de dar estabilidad e insumos precisos, que permitan comprender y llevar a cabo su desarrollo. Esas bases sobre las cuales se ubique este conocimiento ayudarán al desarrollo teórico de la materia y proporcionarán un aporte significativo para su aplicación en torno a las versátiles interacciones humanas.

Por lo tanto, el derecho exige ser repensado desde la multidisciplinariedad; como discurso no solo desprende elementos instrumentales o de forma, que hacen hincapié en la completitud y consistencia normativa, sino que en él también juegan otros tipos de elementos, como la historicidad, la ideología y el poder (Cárcova, 2012).

El derecho no es un instrumento neutral en la organización de la vida social, por el contrario se enmarca en un contexto concreto, como una práctica que se estructura desde el discurso. El relato jurídico mantiene una narratividad (leyes, expedientes, latinismos) y como tal debe ser sometido a un análisis de las instancias intertextuales 
que inciden en su formación y aplicación, ese espacio paradojal en que el derecho expone y descubre, pero al mismo tiempo calla y opaca.

En este sentido, Francois Ost (2007) indica:

¿Quién se extrañará de que, en esas condiciones, el Derecho sea, a la vez, estable y efímero o experimental, duro y blando (hard y soft), ¿coyuntural y principal? (...). ¿Quién no se percata de que el Derecho proviene a la vez del centro del orden normativo mismo y de la periferia, del desorden (o de órdenes distintos) que prevé en el exterior? (p. 121).

El texto jurídico no solo debe pensarse como una instancia marcada por la intertextualidad, sino que al mismo tiempo es un entramado discursivo pasible de ser interpretado:

Pensar el derecho como una práctica social discursiva significa asumir que consiste en algo más que palabras; que también es comportamiento, símbolos, conocimientos. Que es al mismo tiempo, lo que la ley manda, los jueces interpretan, los abogados argumentan, los litigantes declaran, los teóricos producen, los legisladores sancionan o los doctrinarios critican, además, lo que a nivel de los súbditos opera como sistema de representaciones (Cárcova, 2012, p. 163).

En un primer nivel encontramos las estructuras del discurso jurídico, en tanto que en un segundo nivel localizamos las interpretaciones acerca de dichas normas realizadas por los operadores jurídicos. Ellos producirán y darán sentido al derecho, que como práctica social adquiere sus sentidos en la práctica que de un modo u otro interviene en su construcción, lo que en parte el filósofo austríaco Ludwig Wittgenstein (2017) entendía como “juegos de lenguaje”, en donde el lenguaje es heterogéneo.

Por ello, no solo se debe dar cuentas de la estructura del derecho sino también de la función que tiene para los operadores jurídicos; es decir, se debe tener en cuenta tanto el acto que crea simultáneamente al sujeto intérprete como a la obra interpretada. No hay obra sin sujeto y viceversa. Y decimos sujeto, porque lejos está de ser definido como autor o lector; el papel del productor desde la teoría literaria contemporánea, empieza a ser de cuestionada existencia participativa en el acto creativo de la lectura.

En su obra ¿Qué es un autor?, Foucault (2010) expone, en lo que parece ser un diálogo permanente con la obra de Roland Barthes, que "la función-autor es característica del modo de existencia, de circulación y de funcionamiento de ciertos discursos en el interior de una sociedad" (p. 21). La crítica se dirige a la figura del autor 
que pretende ser puesta como un hecho fundamental; sin embargo, dependiendo de las condiciones de formación del discurso exigirá mayor o menor participación (Foucault, 2010, p. 21).

El autor no es un simple elemento del discurso, sino que ejerce un determinado papel: garantiza un orden, delimita, ordena, excluye y opone textos. Su aparición dependerá de las intenciones de continuidad del relato establecido, dejando por momento espacios al segundo autor de la obra, el lector. El autor no es más que una de las especificaciones posibles de la función-sujeto, no es indispensable la permanencia de su forma y existencia.

En este sentido, las perspectivas de la estética de la recepción impulsan el análisis de las mutaciones de los códigos culturales, su proceso de decodificación del significado y el uso de los textos, y por tanto, Los modos de expresión del ámbito jurídico, no serán ajenos a estos considerandos.

\section{Ricouer y la textura de los intérpretes}

En el ámbito del derecho, el legislador ha segmentado la realidad en un plexo normativo y ha "desaparecido" ${ }^{2}$ de la escena; la norma queda allí, la sociedad pide que hable y el juez "con su prudencia y sana crítica" tendrá que hacerlo. La cuestión interpretativa será un extenso debate en el área jurídica y quizá los aportes desde la lingüística puedan echar luz sobre este fenómeno que de a poco se separa, como lo indica Ricoeur (1983), de la concepción hermenéutica romántica de Schleiermacher y Dilthey, que proponen comprender al autor mejor de lo que él mismo pudiera comprenderse.

En este proceso interpretativo de la norma hay un "intérprete" situado frente al texto, que tendrá que estructurar la subjetividad que su autor (el legislador) intentó plasmar. La intertextualidad normativa es mediada por una interrelación de lecturas sujeta por lo que Jauss (2000) llama un "horizonte de expectativas".

Tal como Ricoeur (1983) lo expresa en Tiempo y narración, el texto implica la pre-comprensión de un mundo común; en ese acto, el texto es suspendido del mundo de su referente, situación necesaria para que la obra no se cierre sobre sí y al mismo tiempo se abra a segundos referentes, en este caso, a los intérpretes.

Es por ello que consideramos que el derecho también se imprime en este espacio en tanto suspende su referente y necesita ser reinterpretado, reestructurando su sentido. Su primer obrador desaparece ante la injerencia de la figura del nuevo autor, el juez.

2 Recurso metafórico, en tanto consideramos que el leģislador cumple una función elemental en la formación del discurso jurídico. 
La imagen implica la caracterización de un determinado modo de ser del discurso jurídico. El hecho de tener una determinada figura que aparece en una instancia específica y que nos insta a decir "esto ha sido decidido por un juez", implica que el discurso no es un acto indiferente y pasajero, sino que se recibe de una determinada manera. La figura del segundo referente condiciona la recepción del texto por parte de los individuos que conforman el tercer nivel, la sociedad.

Esa aceptación expresa (legalidad) y tácita (legitimidad) que la figura del juez reúne como autor e intérprete, exige que pensemos en el vacío de su existencia en términos de nombre propio: "el nombre de autor no es pues un nombre propio como los demás" (Foucault, 2010, p. 19). La implicancia del juez-autor condiciona nuestra forma de concebir el discurso jurídico.

Su muerte o inexistencia no tiene que ver solamente con una ausencia física del sujeto, sino con la ausencia de un referente particularizado, con la indeterminación del hablante o bien, con la aceptación de la voz de autoridad en tanto su significado no permite lugar a la redefinición conceptual.

\section{Ruidos y silencios en torno a lo jurídico}

En la disección del lenguaje jurídico, observamos significados en constante movimiento, múltiples y necesarias intertextualidades, capas discursivas, recorridos caóticos, arbitrarios e inciertos en los que se superponen una miríada de enunciados.

Sin embargo, no debemos pensar que el terreno comunicativo es imposible, en tanto cada sujeto responde y posee una realidad complejamente diferenciada de otros, sino considerar que aquellos sonidos que emitimos y hemos dado en llamar lenguaje poseen una genealogía cargada de poder, de fuerzas en pugna, historia, transformaciones etimológicas y recursos lingüísticos, po lo que no son el resultado de simples y arbitrarias creaciones o instrumentos apriorísticamente ínsitos en los sujetos.

Parafraseando a Cárcova (2012), podemos decir que los textos poseen esa interesante función paradojal de mostrar y ocultar, así como sus tintes de opacidad. Esta opacidad que tiñe al derecho, la utilización del mismo lenguaje para ocultarse y encriptarse, con todo lo que implica en materia de saber-poder, un espacio en el que solo algunos juristas pueden hablar, conocer y participar.

Todo discurso dice y desdice, expone a la vez que esconde algo, está allí para ser interpretado y hablado: "Ciertas instituciones, normas o prácticas cumplen una función distinta de la que "dicen" cumplir. Que se despliegan ideológicamente, es decir, en un doble juego de alusión y elusión, de reconocimiento y desconocimiento" (Cárcova, 2012, p. 150). 
El derecho nos une a la vez que nos separa, nos iguala a la vez que nos desiguala, nos enseña en un ámbito en el que nos excede la miríada de leyes, reglamentos, decretos, ordenanzas y dictámenes que surgen a diario. La presunción del conocimiento de la ley por todos los individuos contrasta con una práctica judicial en donde el derecho es desconocido o no comprendido por la mayoría de los individuos. Un abismo entre el derecho y los sujetos a los cuales se dirige y pueden hacer uso del mismo. Sujetos atravesados por un sinfín de normativas escritas en un lenguaje hermético, apoyado en enrevesados tecnicismos del que harán uso los instrumentos jurídicos:

Una vez más: el poder asentado en el conocimiento del modo de operar del derecho ejerce, en parte, a través del desconocimiento generalizado de ese modo de operar. La preservación de ese poder requiere la reproducción del efecto de desconocimiento. Requiere, en fin, opacidad (Cárcova, 2007, p. 164).

Frente a este panorama, consideramos que el papel del receptor, lector, intérprete, ejecutor, actor $y$, en definitiva, de todo sujeto frente a un mensaje no es solo de mera recepción o ejecución, sino que hay una participación activa del sujeto que recibe el mensaje y lo reinterpreta. Así, todo proceso comunicativo lleva consigo una multiplicidad de implicancias. Cárcova (2009) da cuenta de ello en su artículo “ ¿Hay una traducción correcta de las normas?", en el que indica que para actualizar estructuras de sentido se necesita tanto de creadores como de intérpretes, y una audiencia que recepte y dé su devolución al respecto. Al igual que una partitura dispuesta a ser interpretada, ya en otro tiempo, otro espacio y por otro sujeto diferente de su autor, el lenguaje participa en una constante "traducción", dando como resultado un complejo entramado de discursos culturales, políticos y hermenéuticos, entre otros. No hay discurso sin hablante e intérprete.

Tal como se distingue: "El derecho tiene, junto a una función positiva, también una función negativa que es intrínseca a su propia naturaleza” (Cárcova, 2012, p. 146). Muchos son los documentos que nos permiten, no solo entender lo que sucede en el contexto en el cual son realizados y puestos en marcha, sino observar las incidencias de los acontecimientos pasados y sus proyecciones futuras:

La autoridad depende de la existencia de un núcleo determinado de significados, porque en su ausencia no hay una manera normativa o pública de analizar lo que alguien dice o escribe, con el resultado de que la interpretación se convierte en un asunto de análisis individuales y privados, ninguno de los cuales se somete a verificación o corrección (Palti, 2012, p. 232). 
Kristeva (1997), pionera del desarrollo del término de intertextualidad, indica en torno a ello que el significado de un texto no se transfiere, sino que es mediado por una serie de códigos que involucran otros textos.

Todo lo expuesto intenta asentarnos sobre una base sólida desde la cual poder analizar cómo se establece el sentido del discurso jurídico en su totalidad (normas, teorías, sentencias) y examinar cómo los principales actores jurídicos intervienen en esa producción. La tarea del legislador parece ser la de un sujeto que ha hecho una enorme obra artística; lo que sigue es tarea del juez. Este es quien deberá pulir la obra, ponerle el título correspondiente y ubicarla en la sala de exposición que le parezca más pertinente. Pero no todos los jueces deciden de la misma manera en lo que al derecho respecta (Cárcova, 2012, p. 155).

\section{Nuevos espacios críticos para desmontar lo pensable en términos iusfilosóficos}

Es necesario dar cuentas que, desde una perspectiva iusfilosófica, el derecho es pasible de ser analizado por una multiplicidad de posiciones y ópticas. La pretendida asepsia metodológica de determinadas posiciones iusfilosóficas que intentan reducir al derecho en pura normatividad, permite entender qué es el derecho y cómo se ejerce. La tarea que los jueces realizan involucra otras actividades aparte de la aplicación de las leyes generales a casos particulares. La idea de subsunción que predomina como argumento justificativo en torno a la interpretación judicial no revela los mecanismos que se emplean, así como tampoco explicita si el proceso es puramente intelectual o si participan elementos volitivos, lo que implica que los magistrados realicen una tarea puramente retórica y de cuestionable utilidad ante un proceso significativamente más complejo. El estudio de un determinado caso judicial no puede limitarse al análisis de las normas que lo contienen sino a los sujetos que participan, tal como jueces, fiscales, partes, testigos y peritos.

Ello nos indica que las interpretaciones y el análisis que los jueces hagan del derecho no son un terreno signado por el consenso y el acuerdo compartido, sino que, por el contrario, cada postura dará su perspectiva en torno a cada una de las aristas que conforma el derecho en su totalidad.

En esta instancia de análisis, consideramos necesaria la participación de las teorías narrativistas en el derecho a los fines de que tanto la lingüística como la hermenéutica permitan descifrar el sentido oculto detrás del sentido aparente que los actores jurídicos imprimen a la normas, al mismo tiempo que dan cuenta de las valoraciones, intereses, ideas y perspectivas que cada uno utiliza. 
El discurso jurídico se construye desde la subjetividad, ya que en él siempre hay elección y selección, lo que implica, además, que no se pueda establecer una única forma de producción. El carácter discursivo desde el cual se constituye el derecho (normas, producciones teóricas) es lo que nos lleva a sostener que dicho espacio se materializa como proceso social de producción de sentido. Hay una constante circulación de sentido, más que un discurso de la verdad, aunque ésta haya sido una constante voluntad en la historia del derecho; ${ }^{3}$ de este modo, ningún individuo tiene el privilegio de poder establecer la correcta interpretación del derecho, ${ }^{4}$ pues la circulación del sentido jurídico es constante, y consiste en algo más que palabras.

Estas perspectivas de análisis narratológicas adquieren mayor relevancia en torno al análisis del fenómeno jurídico como discurso. Si pensamos, por ejemplo, en una sentencia como acto jurídico veremos su organización discursiva. El acercamiento y posterior decisión del juez se dará por medios de informes, escritos, comentarios y pruebas que le irán acercando para desentrañar "lo verdadero". Sobre los hechos, el magistrado no ha participado de manera presencial, por lo que podría decirse que este distanciamiento "corrompe" la verosimilitud entre las prescripciones legales y la realidad.

La realidad jurídica es construida desde la interpretación. Hay un gran número de participantes que inciden en dicha formación. La heterogeneidad y complejidad de la comunicación, en donde se exige la decodificación de sus enunciados, dan cuentas de que no se trata de un proceso unívoco.

Lejos de pensar que estas resignificaciones del relato jurídico lo conviertan en un espacio anómico, permiten su actualización y adecuación a las situaciones sociales actuales, caracterizadas por sus cambios constantes y vertiginosos; de este modo, la perspectiva intertextual en materia jurídica surge como un intento de visibilización y formación de un derecho más integral, capaz de escuchar y hacer participar otras perspectivas, con el fin dar una respuesta más completa a los dilemas que se le presentan. Entelman (1982) sostiene que:

\section{(...) se debe proveer de elementos para la construcción de una} teoría suficiente para desentrañar la racionalidad jurídica subyacente al discurso; por otro lado, elementos para la construcción de

3 Véase la práctica de la indaģación judicial, con sus inicios en la Edad Media, que se constituyó como una forma de adquisición y transmisión para alcanzar no solo la verdad jurídica sino la verdad en otros tipos de saberes: "Una manera de autentificar la verdad, de adquirir cosas que habrán de ser consideradas como verdaderas y de transmitirlas" (Foucault, 1991, p.66).

4 En este sentido, Duquelsky (2015) hace referencia al artículo no 79 del Código Penal de la Nación Argentina, y resalta que "en el caso del homicidio simple existen las 6.205 opciones que representan la cantidad de días que van desde los 8 a los 25 años de prisión” (p. 128). 
una teoría que contenga los conceptos necesarios para el control de producción y asignación de sentidos de tal discurso; $y$, finalmente, elementos para la construcción de una teoría suficientemente explicativa del rol del sujeto en el proceso discursivo, capaz de derivar de las reglas de formación especiales del discurso jurídico que designan esos sujetos, las imposiciones implícitas para la distribución del sentido (pp. 103-104).

Todas las herramientas analíticas desde la cuales se puede analizar y entender el derecho como relato hacen que no se lo conciba como una reproducción y explicación autómata de la situación histórica en que se presenta, sino que es la invitación a recurrir a otros discursos como forma de una interpretación más amplia y profunda; son conjuntamente un análisis cultural, político, económico, social y cognitivo, entre otros. No podemos ligarnos a lo meramente estructural y formal de un discurso, y aun si deseáramos hacerlo, tendríamos que saber que la misma estructura es efecto de otros discursos antecedentes.

Entender el derecho como relato nos da ciertas pautas que, si bien se venían considerándose desde la lingüística, nunca se habían esquematizado y menos aun, ubicado desde la óptica del poder, desde el cual participan estructuras de dominación en las relaciones, por más nimias que estas sean.

Los tonos circunstanciales, las frases de poca importancia, las ideas que menos se sustentan, las metáforas que embellecen, y en definitiva, todos esos recursos que cualquier lector pasaría por alto en su ansiosa búsqueda por entender la finalidad del texto, hacen parte del discurso jurídico.

Teniendo en cuenta lo anterior, queda la sensación de que enfrentarnos al análisis del discurso jurídico es soportar las variaciones de sentido y todo lo que ello provoca en nuestro mundo simbólico históricamente construido. Posicionarse frente a esta perspectiva como actores jurídicos es estar dispuestos a escuchar un discurso que posiblemente hemos omitido de manera intencional o que no queremos escuchar, es pararnos sobre un terreno endeble que empezará a estremecerse instantáneamente, y no habrá arquetipos, conceptos cerrados, conocimientos unívocos ni seguridades epistemológicas en donde sostenerse; es el cuestionamiento constante y la impostura ante lo que está dicho y presumido bajo el umbral de la "naturalidad"; es el desengranaje y deconstrucción de la normalidad, para luego intentar unir las piezas y ver qué figura verdaderamente escondía el borroso rompecabezas discursivo.

Como hemos analizado en las líneas anteriores, intertextualidad e interpretación serán dos aspectos importantes para poder analizar la conformación del fenómeno jurídico, pero consideramos que es necesario su análisis bajo un tercer elemento, el 
ficcional, en donde el discurso se eclipsa bajo formas diferentes de las que su discurso parece hacer alusión. Esta dualidad contradictoria, lejos de ser considerada una falla que atenta contra su existencia, será un elemento importantísimo para su constante funcionamiento y reproducción.

\section{Ficción y derecho}

Al principio se creyó que Tlön era un mero caos, una irresponsable licencia de la imaginación; ahora se sabe que es un cosmos y las íntimas leyes que lo rigen han sido formuladas, siquiera en modo provisional. Tlön, Uqbar, Orbis Tertius, Jorge Luis Borges

\section{Ser o deber ser, ésa es la cuestión}

La ficción permite la ruptura y la resignificación de los espacios de "lo real", y al mismo tiempo intenta introducirse y participar en ese abismo inasible, en tanto propone un espacio infinito dentro de la finitud conceptual que implica la realidad. Es así que los cortes y límites entre ambos espacios no serán claros y racionalmente delimitados.

Como lo expondrá Mari, las ficciones se desarrollan desde la categoría del "como si" llamada por Hans Vaihinger (2002) como "lo conscientemente falso". El "como si" tiene una función de conocimiento, que permite comprender el poder por cuenta de otras escenas: la realidad histórica que lo instaura se enmarca desde un discurso racional del orden. "El principio del 'como si' instaura el contenido de la convención misma que hace operantes y válidas las leyes y disposiciones del poder" (Marí, 1986, p. 106).

Lo ficcional reviste un carácter puramente ideológico:

No hay un ejemplo más conocido y preferido de las ficciones que el de la ciencia jurídica. Existe en su empleo "un mecanismo psicológico" que consiste en que subsume un caso aislado, particular (ein einzelner Fall) en una forma imaginativa, representativa, (Vorstellungsgebielde), no determinada, en donde el proceso de percepción es totalmente análogo. El fundamento radica en que no pudiendo captar las leyes todos los casos particulares, ciertos casos de naturaleza ajena a la norma (abnormer Natur) son considerados "como si" pertenecieran a ella (Marí, 2002, p. 307). 
La ficción desafía y redefine los límites mismos de la ficción, por eso, desde esta posición lo que percibimos en realidad es una trama discursiva construida que se imprime en los fenómenos, de allí las múltiples formas de concebir la realidad.

Si continuamos con esta línea de análisis, vemos que el discurso científico no solo se constituye desde lo fenomenológico en tanto base empírica, sino que sus postulados revisten un carácter ficcional que permite mantener la base del conocimiento y al mismo tiempo disimular los mecanismos que inciden en dicha formación epistemológica. Por eso desde una perspectiva científica podemos visibilizar cómo el saber jurídico se constituye y despliega desde la discursividad, lo que nos insta a indagarlo bajo dos categorías de análisis; por un lado, desde la intertextualidad como examen de los elementos que intervienen en el desarrollo de su estructura, y por el otro, desde lo ficcional, como instrumento que permite su paradojal funcionamiento.

Recursos como los entramados textuales, las relaciones inconexas, las palabras puestas minuciosamente y otras intencionalmente vedadas son insumos comunes en las obras literarias, pero creemos que también se desarrollan en otros discursos del saber, entre ellos el jurídico. Allí se da ese espacio paradojal de lo ficcional en el cual se debaten las figuras de lo real, lo inexistente, la ideología, el poder y la voluntad de verdad. Teniendo en cuenta lo anterior, Cárcova expone que

Las nociones de ficción y verdad han jugado un papel determinante en la historia del derecho occidental (...). Como elementos estructurantes del discurso jurídico (....). El derecho, pensado como tecnología social, como regla de juego básica constitutiva de un cierto orden, no puede funcionar sin el sutil y complejo enlace de estos conceptos (2012, p.27).

Ese rol paradojal implica sostener que el derecho cumple un rol formalizador y reproductor de las relaciones sociales establecidas, al mismo tiempo que las remueve y transforma; además, reúne en un mismo estamento una función conservadora y reformadora.

\section{Divertimentos ideológicos en el derecho}

El discurso jurídico instituye, consagra y construye. Es por ello que no solo se debe indagar las líneas escritas del discurso jurídico, sino también aquellas que se omiten; las clasificaciones teóricas, las finalidades expresas, el orden de los artículos y la construcción de las normas, se piensan como lo único posible y manifiesto, pero en simultáneo otras funciones se mantienen latentes y disimuladas: 
Se trata de un discurso que, paradójicamente, al tiempo que legitima las relaciones de poder existentes, sirve para su transformación. De un discurso cargado de historicidad y de ideología, pero que no reproduce de forma mecánica la estructura de la sociedad. De un discurso que deposita en el imaginario colectivo, las ficciones y los mitos que dan sentido a los actos reales de los hombres (...). De un discurso que incluye a la ciencia que pretende explicarlo (Ruiz, 2003, p. 1).

El derecho está unido a una construcción inconsciente y oculta, que delimitará sus contornos cognoscibles. Dentro de dichas problemáticas se encuentra entre otras, la ideológica. Allí los intereses, los significados disimulados y el poder forman una estructura cerrada, que se autoabastece y se transforma sobre sí misma.

Dentro de este campo, la ideología funciona como el marco de representación sobre el que se construyen y desenvuelven los sujetos en sus condiciones reales de existencia, con la finalidad de reproducir los mecanismos de hegemonía social. Lo ideológico crea el mapa imaginario en el cual desarrolla sus mecanismos de funcionamiento. Pone nombres, da derechos, permite la libre expresión, pero todo ello es previsto; es una doble manifestación, en tanto alude y elude, reconoce y desconoce. En definitiva, lo ideológico implica "un sistema, de nociones, de ideas, principios morales, leyes, arte, teoría, etcétera, presentes de una manera práctica desde el 'sentido común' hasta las instituciones (jurídicas, políticas y educativas) y de una manera teórica (discursos morales, teológicos, filosóficos)" (Ruiz, 1991, p. 152).

Por lo tanto, el discurso jurídico exige ser leído desde el poder y desde la ideología. En este sentido, Marí (1986) expone que el discurso del orden es el lugar de la razón y el espacio de la ley, en el cual:

La fuerza encuentra dentro del dispositivo del poder su modo más racional de comunicación social al apropiarse de las técnicas con que las normas jurídicas transmiten y transportan con el nombre de coerción, coacción, y sanción, es decir, con los mecanismos de la obediencia y control social del derecho. Todo ello exige una estructura de movilización de creencias discursivas y extraordinarias que será el lugar del imaginario social, la tierra natural de las ideologías teóricas y prácticas (p. 97).

Discurso que se inserta: "En montajes de ficción, soportes mitológicos y prácticas extradiscursivas" (Marí, 1986, p.93). Es así que lo significado desde el derecho, no solo está en los elementos que visibiliza ni en su orden normativo, sino en aquellas 
funciones que oculta. Además, posee un importante valor simbólico, constituye el lugar del mito en las sociedades contemporáneas, signadas por la racionalidad. Allí el derecho participa de este aspecto racional porque "tiene una función de conocimiento, porque pertenece al discurso del orden y porque genera las condiciones de su propia existencia ocultando permanentemente su carácter legitimador del poder y su historicidad" (Ruiz, 1991, p. 179).

En este orden de ideas, Fitzpatrick (1998) sostiene que:

El derecho funciona en un mundo social, pero existe separado de él, lo domina (...). Así, el derecho moderno aparece, en una exaltación negativa, como universal en oposición a lo particular, como unificado en oposición a lo diverso, como omnicompetente en contraste con lo incompetente, y como controlador de lo que debe ser controlado. El derecho está imbuido de esta trascendencia negativa en su propio mito de origen, en el cual se sitúa imperiosamente contra ciertos "otros" que concentran las cualidades a las que el derecho se opone (p. 11).

Los espacios de lo ideológico emparentados al discurso jurídico invitan al análisis de las representaciones tanto de los sujetos en su individualidad como en los grupos en que interactúa. La cotidianeidad se traduce bajo instancias de normalidad y generalización, espacio en el cual se ritualizan las conductas y no se permite esclarecer los intereses perseguidos. En esta estructura social determinada se produce el discurso jurídico, por tanto no es ajeno a la forma circunstancial en la que los hombres viven y se relacionan entre sí (Ruiz, 1991, pp. 159-160).

\section{Espacio y expansión del lenguaje jurídico}

El lenguaje deja de ser una mera representación de la realidad, sino que pasa a crearla activamente. No constituye una realidad ejemplar, separada del hombre parlante que disciplina a los individuos con su virtud ontológica. La realidad no antecede al lenguaje, sino que junto a la palabra participan en simultáneo.

Lejos de constituirse como un hecho objetivo, la palabra surge como una empresa individual, el individuo toma la palabra: "Nombrar es llamar a la existencia, es sacar de la nada. Lo que no es nombrado no puede existir de manera alguna" (Gusdorf, 1971, p. 35). Toda conceptualización implicará denominación, precisión, decisión, determinación y limitación de un espacio de la realidad: "La definición particular esta anexada a un interés de poder concreto, puede llamársela ideología” (Berger \& Luckmann, 1993, p. 157). 
No puede sostenerse la universalidad e identificación con un pretendido orden natural del lenguaje en tanto se construye desde un espacio histórico circunstancial. ${ }^{5}$ El lenguaje no solo influye en la experiencia sino que la determina; constituye el mundo a través del cual se desarrolla la sociedad desde sus orígenes grupales como individuales. En este sentido, el teórico literario alemán Iser, quien ha trabajado extensamente sobre esta temática, entiende a la ficcionalización como una necesidad que permite la producción de otros mundos y cuya realidad no se duda aún a sabiendas de que son una simulación. La ficción posee la capacidad de duplicidad, de exceder los límites de lo establecido:

Disfrutar tanto de lo real como de lo posible y poder mantener al tiempo la diferencia entre una cosa y otra es algo que se nos niega en la vida real; sólo puede ser representado en la forma del 'como si' de la ficcionalidad. (Iser, 1997, p. 60)

Siguiendo la línea epistemológica que proponemos, consideramos que la fictio juris también debe ser analizada no solo desde su estructura sino desde su funcionalidad. El hecho de que el derecho haga uso de este recurso nos exige pensar cuáles son las intenciones, no tanto latentes (quizá sean reconocibles en cualquier manual teórico), sino más bien aquellas que se movilizan tácitamente. Lo que se calla, se hace cómplice, participe, se denuncia, se censura, se critica, se resiste o se exige desde lo ficcional, es canal de expresión de lo pensable en el contorno jurídico. Un texto no se constituye de manera autónoma, sino que responde a la multiplicidad discursiva en la que se germina y forma.

\section{Ficciones, funciones y fines}

En la igualación algo se deja afuera. A través de la norma como relato único, se opacan las desigualdades en pos de una supuesta igualdad. Tanto el papel aparentemente disfuncional e indiferente en el que participa y actúa el sujeto desde el derecho, como la igualación desde el discurso normativo o el conocimiento del andamiaje legal, funcionan a nivel ficcional. Es decir, cuando el derecho nos habla no logramos discernir cuáles son las intenciones de ese acto discursivo ni cuáles son sus condiciones de aplicabilidad. Lo que consideramos real, muchas veces son configuraciones ficcionales que no nos permiten darnos cuenta de cómo verdaderamente nos situamos frente al derecho.

5 El antropóloģo y lingüista Edward Sapir entiende que el lenģuaje de una comunidad humana dada, que habla y piensa en esa lengua, es el orģanizador de su experiencia y confiğura su mundo y su realidad social gracias a esa función. En cada lenguaje se halla contenida una concepción particular del mundo (Schaff, 1967). 
Numerosas categorías jurídicas pueden ser desmanteladas mostrando la fragilidad de los andamiajes sobre los cuales están construidas. Si extraemos términos como prudencia, discernimiento y buen juicio en la interpretación jurídica, veremos que en concreto generalizan un hecho que en realidad tiene mayores intersecciones e implicancias; esto es definido por Calvo González como "ajuste narrativo"; así, según el autor, el juez:

Revisa, compara, intersecta, discrimina, rehúsa, y también prefiere, opta, elige, e igualmente admite, y enlaza y elabora y armoniza hasta construir la coherencia narrativa de lo discutido sobre los hechos y, por coherencia normativa, fabricar el ensamblaje jurídico anudado a ella. Y así dice los hechos y dice el derecho en un relato, el veredicto, que es verdad judicial" (...). No sólo se estabiliza o dilucida el pasado, sino que el pasado se decide, dando a ver con ello una manifiesta voluntad de dominio que afecta el presente y, sobre todo, alcanza al porvenir en la condición de cosa juzgada (Calvo González, 1999, p. 14-15).

Esta última cosa juzgada, como indicadora de que se ha encontrado la correcta interpretación y aplicación de las leyes generales al caso concreto, el "Veredicto (vereverdad/dictum-dicho) que tiene carácter performativo” (Cárcova, 2012, p. 297). La cosa juzgada permite movernos en un "terreno seguro". Sin embargo, dicha institución reviste la calidad de una ficción jurídica, técnica y normativa, que amplía el espectro de cosas comprensibles dentro de su discurso. Desde ella, se intentan asumir algunos fenómenos como ciertos, que no suceden o aún no han sucedido. Pero la ficción en el derecho no solo amplia el espectro de cosas comprensibles dentro de su discurso, sino también es reproductora de las relaciones desiguales de poder y dominación, insertándose en el mundo del imaginario social y simbólico.

Marí (2002), expone al respecto: "Las ficciones suministraban un arsenal de técnicas para eludir los obstáculos que la realidad levantaba frente a las acciones humanas, proporcionando una autentica alquimia, una potente herramienta para transformar la realidad" (p. 266). En un mismo sentido, la lingüista María Laura Pardo (1994) complementa: "ficción que se hace visible en el texto de las sentencias;

\footnotetext{
6 "La cosa juzģada es una curiosa institución jurídica. Establece que, aģotados los recursos procesales, el caso se halla definitivamente resuelto y no puede seguir debatiéndose judicialmente. Es una institución curiosa porque concede una suerte de sacralidad leģal a una decisión en ciertas circunstancias formales, cerrando los ojos ante la posibilidad de que tal decisión sea contraria al propio sistema jurídico que así la bendice". (Guibourg, 2017, p. 1)
} 
esta ficción surge de la necesidad de otorgar al texto objetividad y poder, más que de extender o ampliar el mundo de las cosas" (p. 26).

En este espacio el derecho construye sus verdades, marca su legitimidad y establece el espacio de lo justo y lo injusto, ${ }^{7}$ estableciendo categorías jurídicas instituidas por una compleja tecnología que se sustenta en precarios criterios de verdad desde la fictio juris. De este modo, el derecho aglutina a la vez que separa, iguala a la vez que desiguala, exige saber al mismo tiempo que su largo listado de leyes, reglamentos, decretos, ordenanzas y dictámenes de leyes se saben imposibles de conocer en su totalidad. ${ }^{8}$

Sumado a los principales argumentos que encuentran las ficciones jurídicas, como la simplicidad que otorgan para tratar determinados dilemas, también vemos que por momentos invisibilizan las condiciones reales en las que los individuos se encuentran: vivienda digna, buena fe o buen padre de familia son conceptos cuya definición dista de ser cerrada y omnicomprensiva.

La ficción hegemoniza todos los ámbitos de la realidad, lo que lleva a que sean sostenidos como verdaderos y resueltos, esto conduce a que no se la perciba como una técnica ideológica sino como parte constitutiva y necesaria para el desarrollo social. Ese espacio vedado no se hace palpable ni materialmente visible, sino que se reviste bajo las imágenes del sentido común, lo verdadero, el orden.

\section{Conclusiones}

Los trazos, las oraciones y las pautas exponen (al mismo tiempo que ocultan) toda una percepción del sentido contextual, y el derecho no es ajeno a este espacio. La voluntad de verdad aferrada a sus enunciados imprime en cada postulado la idea de una forma de entender los fenómenos que se conocen, pero la forma en que se estructuran llevará consigo toda una cosmovisión e intencionalidad de lo que quiere constituirse como derecho y, dada su injerencia en el entorno, toda una visión de los elementos que conformarán la sociedad.

7 Enunciados que leģitiman y a la vez opacan las condiciones reales del derecho en la sociedad, tales como el principio de inexcusabilidad, la igualdad ante la ley o las condiciones carcelarias, entre otros. Los derechos en apariencia pretenden incluirnos y hacernos activos partícipes de una historia en la cual creemos ser actores principales, pero en realidad somos meros espectadores: "Pero también está en la teoría de los conmorientes, en la persona jurídica, en el carácter de bien inmueble atribuido a un papel que instrumenta derechos reales sobre tal inmueble, en la cosa juzģada, en el carácter de inmuebles por accesión atribuido a ciertos bienes muebles, en la ausencia con presunción de fallecimientos, en la obliģaciones propter rem o cabalgantes, en el caso de los mellizos que la ley considera a todos los efectos como iģual edad, aunque hubieran nacido aún en diversos días" (Cárcova, 2012, p. 38).

8 La presunción del conocimiento de la ley por todos los individuos contrasta con una práctica judicial en donde el derecho muchas veces es desconocido o no comprendido por la mayoría de los individuos, atravesados por un sinfín de normativas escritas en un lenguaje hermético, apoyado en enrevesados tecnicismos del que harán uso los diferentes instrumentos jurídicos. 
Significados en constante movimiento, enunciados superpuestos que se van sedimentando, recorrido caótico, arbitrario e incierto en el que se va desarrollando el saber jurídico, dan cuenta del concepto de intertextualidad. En este orden de ideas, se destacan el concepto de interpretación, que en sus textos exige la participación de un lector que cambiará constantemente el sentido del texto, y el de la la ficción, en tanto permite la ruptura y la resignificación del espacio de lo que consideramos "lo real"; así, se da ese espacio paradojal en el cual se debate la figura de la real y lo inexistente, la ideología y la voluntad de verdad.

Los conceptos de intertextualidad y de ficcionalidad son inescindibles y complementarios entre sí y, al mismo tiempo, devienen directrices no solo en su obra específicamente, sino en el análisis de todo tipo de discurso entre los cuales destacamos el discurso jurídico.

Las múltiples interpretaciones que inciden en las aplicaciones y transformaciones del espacio jurídico, sumadas al papel performativo que se trasluce desde la ideología, vienen a dar cuenta del aspecto sectorial y particular que tiene el derecho; su lenguaje jurídico se desarrolla y construye desde la intertextualidad. Por ello consideramos que el discurso jurídico se constituye apoyado en un sustento empírico, pero al mismo tiempo signado por una fuerte impronta ficcional.

Queda esa sensación de que enfrentarnos al análisis del discurso jurídico; es soportar las variaciones de sentido y todo lo que ello provoca en nuestro mundo simbólico históricamente construido. Posicionarse frente a esta perspectiva como actores jurídicos es estar dispuestos a escuchar un discurso que posiblemente hemos omitido de manera intencional o no queremos escuchar. Es pararse sobre un terreno endeble que empezará a estremecerse instantáneamente, y no habrá arquetipos, conceptos cerrados, conocimientos unívocos ni seguridades epistemológicas en donde sostenerse. Un cuestionamiento constante y la impostura ante lo que está dicho y presumido bajo el umbral de la "naturalidad". El desengranaje y deconstrucción de la normalidad, para luego, intentar unir las piezas y ver qué figura verdaderamente escondía el borroso rompecabezas discursivo. Aunque se nos vaya la vida en saber lo que se esconde detrás de todo ese cúmulo de hechos y palabras; "Quizá del otro lado de la muerte sabré si he sido una palabra o alguien" (Borges, 2013 [1981], p. 560).

\section{Referencias}

Adorno, T. W. (1992). Teoría Estética. Madrid: Editorial Taurus.

Althusser, L. (2005). La filosofía como arma de la revolución. Buenos Aires: Editorial Siglo XXI. 
Bachelard, G. (2000). La formación del espíritu científico. Buenos Aires: Editorial Siglo XXI.

Badiou, A. (2007). Justicia, filosofía y literatura. Rosario: Editorial Homo Sapiens.

Bajtín, M. (1991). Teoría y estética de la novela. Barcelona: Editorial Taurus.

Barthes, R. (2003). El placer del texto. Lección inaugural. Buenos Aires: Editorial Siglo XXI.

Barthes, R. (2003). Mitologías. Buenos Aires: Editorial Siglo XXI.

Barthes, R. (2013). El susurro del lenguaje. Buenos Aires: Editorial Paidós.

Berger, P. y Luckmann, T. (1993). La construcción social de la realidad. Buenos Aires: Editorial Amorrortu.

Borges, J. L. (1974). Obras completas. Buenos Aires: Editorial Emecé.

Borges, J. L. (2012). Cuentos completos. Buenos Aires: Editorial Sudamericana.

Borges, J. L. (2013). Poesía completa. Buenos Aires: Editorial Debolsillo.

Calvo González, J. (1996). Derecho y narración: materiales para una teoría y crítica narrativista del $D^{o}$. Barcelona: Editorial Ariel.

Calvo González, J. (1999). La verdad de la verdad judicial (Construcción y régimen narrativo). Revista Internazionale di Filosofía del Diritto, I. Disponible en http://webpersonal.uma.es/ jcalvo/docs/verdadjudicial.pdf

Calvo González, J. (1999). Verdad (Narración) Justicia. Málaga: Editorial Universidad de Málaga.

Cárcova, C. M. (2009). ¿Hay una traducción correcta de las normas?. Revista Electrónica del Instituto de Investigaciones "Ambrosio L. Gioja”, III(4), 33-42. Disponible en http://www.derecho.uba.ar/revistagioja/articulos/R0004A003_0004_ investigacion.pdf

Cárcova, C. M. (2007). La opacidad del derecho. Madrid: Editorial Trotta.

Cárcova, C. M. (2012). Las teorías postpositivistas. Buenos Aires: Editorial Abeledo Perrot.

Courtis, C. (comp.). (2009). Desde otra mirada. Buenos Aires: Editorial Eudeba.

Deleuze, G. (2015). Foucault. Barcelona: Editorial Paidós. 
Derrida, J. (2008). Fuerza de ley. El "fundamento místico de la autoridad". Madrid: Ed. Tecnos.

Duquelsky, D. (2015). El rol del juez en una sociedad democrática. Revista de dereitos e garantías fundamentais, 16(2), 121-148. Disponible en http://sisbib.fdv.br/ index.php/direitosegarantias/article/view/728

Eco, U. (1992). Los límites de la interpretación. Buenos Aires: Editorial Lumen.

Fairclough, N. (1995). Language and power. London \& New York: Editorial Lonhman.

Fitzpatrick, P. (1998). La mitología del derecho moderno. Buenos Aires: Editorial Siglo XXI.

Foucault, M. (1991). La verdad y las formas jurídicas. Barcelona: Editorial Gedisa.

Foucault, M. (1996). El orden del discurso. Madrid: Editorial La Piqueta.

Foucault, M. (2006). Yo, Pierre Rivière, habiendo degollado a mi madre, a mi hermana y a mi hermano. Barcelona: Editorial Tusquets.

Foucault, M. (2008). Las palabras y las cosas. Una arqueología de las ciencias humanas. Buenos Aires: Editorial Siglo XXI.

Foucault, M. (2010). ¿Qué es un autor? Buenos Aires: Editorial El cuenco de plata.

Garrido Domínguez, A. (comp.). (1997). Teorías de la ficción literaria. Madrid: Editorial Arco Libros.

Guibourg, R. (2017). “La cosa juzgada y la constitución”. Filosofía para el derecho: Encuentro jornada de debate interdisciplinario entre filósofos y constitucionalistas", llevado a cabo el día martes 25 de abril de 2017 por el Departamento de Derecho Público y la Maestría en Filosofía del Derecho de la Facultad de Derecho de la Universidad de Buenos Aires, Buenos Aires.

Gusdorf, G. (1971). La palabra. Buenos Aires: Editorial Nueva Visión.

Hernández Marín, R. (1986). Ficciones jurídicas. Doxa, III, 141-147.

Jauss, H. R. (2000). La historia de la literatura como provocación. Barcelona: Editorial Península.

Kelsen, H. (1982). Teoría Pura del Derecho. D.F.: Editorial Universidad Nacional de México.

Kennedy, D. (1999). Libertad y restricción en la decisión judicial. El debate con la teoría crítica del derecho (CLS). Bogotá: Editorial Siglo del Hombre Editores. 
Kristeva, J. (1997). Bajtín, la palabra, el diálogo y la novela. En Navarro, D. Intertextualité: Francia en el origen de un término y el desarrollo de un concepto (pp. 1-24). La Habana: Editorial UNEAC.

Legendre, P., Entelman, R., Kozicki, E., Abraham, T., Marí, E., Le Roy, E., \& Vezzetti, H. (1982). El discurso jurídico. Buenos Aires: Editorial Hachette.

Marí, E. (1980). “Moi, Pierre Riviere...” y el mito de la uniformidad semántica en las ciencias jurídicas y sociales. Revista de la Facultad de Derecho de la Universidad Complutense, 59, 81-110.

Marí, E. (1986). Racionalidad e imaginario social en el discurso del orden. Doxa, III, 93-111.

Marí, E. (1994). El retorno del caso Rivière. Un debate postergado. Doxa, XV-XVI, 883-896.

Marí, E. (2002). La Teoría de las Ficciones. Buenos Aires: Editorial Eudeba.

Marí, E., Ruiz, A. E. C., Cárcova, C. M., Entelman, R., Ost, F., Van de Kerchove, M., \& Kelsen, H. (1991). Materiales para una teoría crítica del derecho. Buenos Aires: Editorial Abeledo Perrot.

Martyniuk, C. (2006). Sobre la norma del gusto, la normatividad del arte y la narración de la justicia. Buenos Aires: Editorial Coyoacán.

Nietzsche, F. (1990). Sobre verdad y mentira en sentido extramoral. Madrid: Editorial Tecnos.

Ost, F. (2007). Júpiter, Hércules, Hermes: tres modelos de jueces. Academia, Revista sobre enseñanza del derecho, 4(8), 101-130.

Palti, E. J. (ed.). (2012). Giro lingüístico e historia intelectual. Buenos Aires: Editorial Universidad Nacional de Quilmes Editorial.

Pardo, M. L. (1994). La ficción jurídica desde la lingüística: actos de habla y ficción. Revista de Llengua i Dret, 22, 25-43.

Ricoeur, P. (1983) Tiempo y narración: Configuración del tiempo en el relato histórico. D.F.: Siglo XXI.

Ruiz, A. E. C. (1985). La Ilusión de lo jurídico. Una aproximación al tema del derecho como un lugar del mito en las sociedades modernas. Crítica Jurídica, 8.

Ruiz, A. E. C. (1991). Notas en torno a los fundamentos sociales del discurso democrático. No hay Derecho, 2(5). 
Ruiz, A. E. C. (2003). El derecho como discurso y como juego. Revista Jurídica Universidad Interamericana de Puerto Rico, 38, 1-5. Disponible en http:// latcrit1.org/media/medialibrary/2014/01/10_uiapr_ruiz.pdf

Ruiz, A. E. C. (2013). Teoría crítica del derecho y cuestiones de género. Colección Equidad de Género y democracia, 6, 40.

Santibáñez Yánez, C. (2007). Los juegos de lenguaje de Fritz Mauthner y Ludwig Wittgenstein. Teorema: Revista internacional de filosofía, 26(1), 83-106.

Sapir, E. (1971). El lenguaje. D. F.: Editorial Fondo de Cultura Económica.

Schneck, P. (2007). Las leyes de la ficción: la retórica jurídica y la evidencia literaria. Revista Europea de Estudios de Inglés, 11, 47-63.

Sloterdijk, P. (2006). Venir al mundo, venir al lenguaje. Valencia: Editorial Pre-Textos.

Vaihinger, H. (1922). Die Philosophie "als ob". Leipzig: Editorial Verlag von Felix Meiner.

Van Dijk, Teun A. (2009). Discurso y poder. Barcelona: Editorial Gedisa.

Wittgenstein, L. (1968). Los cuadernos azul y marrón. Madrid: Editorial Tecnos.

Wittgenstein, L. (1980). Tractatus lógico-philosophicus. Madrid: Editorial Alianza.

Wittgenstein, L. (2017). Investigaciones filosóficas. Madrid: Editorial Trotta. 